Georgia State University College of Law Reading Room

Faculty Publications By Year

Faculty Publications

Summer 2015

\title{
Regulatory Competitive Shelters in the Area of Personalized Medicine
}

Yaniv Heled

Georgia State University College of Law, yheled@gsu.edu

Follow this and additional works at: https://readingroom.law.gsu.edu/faculty_pub

Part of the Administrative Law Commons, Food and Drug Law Commons, and the Science and Technology Law Commons

\section{Recommended Citation}

Yaniv Heled, Regulatory Competitive Shelters in the Area of Personalized Medicine, 21 B.U. J. Sci. \& Tech. L. 287 (2015).

This Article is brought to you for free and open access by the Faculty Publications at Reading Room. It has been accepted for inclusion in Faculty Publications By Year by an authorized administrator of Reading Room. For more information, please contact mbutler@gsu.edu. 


\title{
ARTICLE
}

\section{REGULATORY COMPETITIVE SHELTERS IN THE AREA OF PERSONALIZED MEDICINE}

\author{
YANIV HELED, J.S.D.*
}

\section{INTRODUCTION}

Much has been written about the ramifications of recent Supreme Court decisions in the area of patent subject matter eligibility ${ }^{1}$ on innovation in the area of personalized medicine. ${ }^{2} \quad$ Yet, $^{2}$ regulatory competitive shelters ("RCSs") ${ }^{3}$ have remained largely unexplored as a mechanism for incentivizing innovation in that area, possibly in lieu of patents. Similarly, in a recent report and related guidance documents, the Food and Drug Administration ("FDA") made clear its commitment to streamlining regulation in the area of

* Assistant Professor, Georgia State University College of Law; J.S.D. 2011, LL.M. 2004 Columbia Law School; LL.B. 2000, Undergraduate Diploma in Biology 2000 Tel Aviv University.

I See, e.g., Mayo Collaborative Servs. v. Prometheus Labs., Inc., 132 S. Ct. 1289 (2012); Ass'n for Molecular Pathology v. Myriad Genetics, Inc., 133 S. Ct. 2107 (2013).

2 See, e.g., Elizabeth J. Haanes \& Jaume M. Cànaves, Stealing Fire: A Retrospective Survey of Biotech Patent Claims in the Wake of Mayo v. Prometheus, 30 NatURE BioteCH. 758,760 (2012) (concluding that "Prometheus is a game changer" as it renders invalid most patent claims directed to diagnostic products). For the purpose of this Paper, "personalized medicine" (a.k.a. pharmacogenomics, individualized medicine, and precision medicine) is to be understood broadly as "the tailoring of medical treatment to the individual characteristics, needs and preferences of a patient during all stages of care, including prevention, diagnosis, treatment and follow-up." FoOD \& Drug ADMIN., PAVING THE WAY for Personalized Medicine: fDA's Role in a New Era of Medical Product Development 6 (2013) [hereinafter Paving THE WAY].

3 Broadly defined, RCSs are competitive advantages resulting from statutory bars on regulatory action where such action is otherwise mandated in legislation and would have taken place but for the triggering of the bar; thus, RCSs are the result of an administrative agency's inability to take certain regulatory action that, had such action been taken, would have paved the way for competition in a certain product or market. See Yaniv Heled, Introducing: Regulatory Competitive Shelters, the New Patents, 76 Оню Sт. L.J. 299 (2015). RCSs are also commonly known by other names such as "regulatory exclusivities," "data exclusivities," and "statutory exclusivities," among others. See id. (explaining how these names fail to characterize RCSs with sufficient specificity and sometimes misstate RCSs' function). 
personalized medicine. ${ }^{4}$ These documents, however, also do not address the RCSs available to personalized medicine technologies. This Article seeks to explore the existing landscape of RCSs that are currently available to personalized medicine technologies and highlight further ways in which RCSs may provide incentives for innovation in such technologies.

\section{REgUlATORY COMPETITIVE SHELTERS CURRENTLY AVAILABLE TO PERSONALIZED MEDicine TECHNOLOGY}

Personalized medicine technology can be roughly classified into the following technology categories:

1. Pharmaceutical products meant for use in specific patients exhibiting particular physiological characteristics or pathologies. ${ }^{5}$

2. Medical devices meant for use in specific patients exhibiting particular physiological characteristics or pathologies.

3. Personalized tissues, organs, and vaccines made from or impregnated with a patient's own biological material. ${ }^{6}$

4. Diagnostic devices, tests, and direct-to-consumer ("DTC") kits meant for use independently, or with technologies of the abovementioned categories (1), (2), or (3), including in vitro companion diagnostic devices. ${ }^{7}$

5. Devices and methods for analyzing large quantities of medical and clinical information in order to determine therapeutically relevant correlations, including via algorithms. ${ }^{8}$

4 See PAVING THE WAY, supra note 2, at 2 (referring to the FDA's "many recent efforts to advance regulatory standards, methods and tools in support of personalized medicine and to further refine critical regulatory processes and policies in order to bring about personalized medicine product development").

5 Traditionally, personalized medicine has been thought of as consisting mostly of this type of technologies. As such, some have described personalized medicine as "providing the right treatment to the right patient, at the right dose at the right time." Id. at 6-7.

6 Examples include stem cell therapies, artificial organs (such as a 3D-printed trachea), gene therapies performed on tissue ex-vivo, and personalized immunotherapies. See, e.g., Cedrik M. Britten et al., The Regulatory Landscape for Actively Personalized Cancer Immunotherapies, 31 NATURE BIOTECH. 880 (2013) (describing different courses of treatment for cancer using immunotherapies tailored to a patient's own genetic makeup).

7 Examples include genetic assays of various kinds and genetic sequencing devices. See John T. Aquino, FDA's Clearance of Diagnostic Devices Seen as Aiding Personalized Medicine, HeAlth IT Law \& Industry ReP., Dec. 02, 2013, at 10 (discussing the FDA's clearance of a high-throughput genetic sequencing device and a genetic assay testing for 139 genetic variants of cystic fibrosis); FOOD \& DRUG ADMIN., IN VITRO COMPANION Diagnostic Devices: Guidance for Industry and FoOd and Drug Administration StafF 4-5 (2014) [hereinafter In Vitro Companion Diagnostics GuidanCE] (defining in vitro companion diagnostic devices as "an in vitro diagnostic device that provides information that is essential for the safe and effective use of a corresponding therapeutic product").

8 Notably, some diagnostic products, especially ones meant to predict probabilities of 
6. Databases containing medical information used for or in conjunction with technologies of the abovementioned categories (1)-(5). ${ }^{9}$

All six categories of personalized medicine technologies are potentially subject to RCS regimes administered by the FDA as discussed below.

\section{RCSs for New Products}

Like all new pharmaceutical products, personalized medicine technologies of categories (1) and (3) listed above may benefit from RCSs under the Orphan Drug Act (seven-year market exclusivity), ${ }^{10}$ Hatch-Waxman Act (five-year market exclusivity and four- or five-year data exclusivity), ${ }^{11}$ and the Biologics Price Competition and Innovation Act ("BPCIA") (twelve-year market exclusivity and four-year data exclusivity). ${ }^{12}$ An example is the seven-year orphan drug exclusivity and concurrent five-year new chemical entity ("NCE") exclusivity in the drug Kalydeco (Ivacaftor) under the Orphan Drug Act and the Hatch-Waxman Act, respectively. ${ }^{13}$

clinical outcomes and recurrences, incorporate both a diagnostic component (e.g. a genetic array) and a method of analyzing the data obtained from the diagnostic. See, e.g., Mark Ratner, Kits Herald a New Wave of Genomic Diagnostics for Cancer, 30 NATURE BIOTECH. 1152,1153 tbl.1 (2012) (listing commercially available genomic diagnostic test products that work in conjunction with complex algorithms).

9 An example is the BRCA genetic mutations database held as a trade secret by the company Myriad Genetics, Inc. See Courtenay Brinckerhoff, Myriad's Trade Secret Trump Card: The Myriad Database Of Genetic Variants, PharmaPatents (July 18, 2013), http://www.pharmapatentsblog.com/2013/07/18/the-myriad-database-of-genetic-variants/ (archived at http://perma.cc/BC3V-PQB2).

10 Pub. L. No. 97-414, 96 Stat. 2049 (1983) (codified at 21 U.S.C. $\S \S 360 \mathrm{aa}-360 \mathrm{ee}$ (2012) and 42 U.S.C. $\S 236$ (2012)) [hereinafter $O D A]$.

11 Drug Price Competition and Patent Term Restoration Act of 1984 (Hatch-Waxman Act), Pub. L. No. 98-417, 98 Stat. 1585 (1984) (codified as amended in scattered sections of $15,21,35, \& 42$ U.S.C.).

12 Patient Protection and Affordable Care Act, $\S \S 7000$ et seq., 124 Stat. 119 (2010) (codified at 42 U.S.C $§ 262(\mathrm{k})(7)(2012)$ ).

13 See FoOd \& Drug AdmIN., Patent and Exclusivity Search Results from Query on Appl No 203188 Product 001 in the OB_Rx List, ORANGE BOOK, http://www.accessdata.fda.gov/scripts/cder/ob/docs/patexclnew.cfm?Appl_No=203188\&Pro duct_No=001\&tablel $=$ OB_Rx (last visited Mar. 6, 2015) (archived at http://perma.cc/2CCR-FFBG). Kalydero is a small-molecule drug indicated for the treatment of a specific mutation that is responsible for cystic fibrosis-a disease caused by hundreds of different known mutations-in about $4 \%$ of those suffering from the disease in the United States. See PAVING THE WAY, supra note 2, at 3. Other examples include Xalkori (Crizotinib), Zelboraf (Vemurafenib), and Tafinlar (Dabrafenib), all of which are smallmolecule drugs, that are the subject of seven-year ODEs and concurrent five-year NCE exclusivities. FOOD \& DRUG ADMIN., Patent and Exclusivity Search Results from Query on Appl No 202570 Product 001 in the OB_Rx List, Orange BooK, http://www.accessdata.fda.gov/scripts/cder/ob/docs/patexclnew.cfm?Appl_No=202570\&Pro duct_No=001\&table $1=\mathrm{OB} \_\mathrm{Rx}$ (last visited Mar. 31, 2015) (archived at 
Of particular importance in this respect is the seven-year orphan drug exclusivity under the ODA. As indicated by the FDA, "[d]ata from the last few years indicate that more and more drugs are being designed for small populations, a trend that is consistent with the increasing use of stratification in drug development." 14 It is, thus, quite possible that a continuation of this trend would lead to such levels of specificity in the uses for which drug products are indicated, that a substantially larger percentage of products will be designated as orphan drugs, which would make them subject to the ODA's seven-year market exclusivity.

\section{RCSs for Additional Clinical Testing Leading to New Therapeutic Uses of Already Approved Pharmaceuticals}

\section{A Three-Year Market Exclusivity Under the Hatch-Waxman Act for Conducting Supplemental Clinical Investigations Leading to Approval of an Existing Drug for Treatment of a New Condition ${ }^{15}$}

This exclusivity seeks to incentivize additional clinical investigations of already-approved pharmaceutical products to test their potential benefits in the treatment of additional medical conditions. Because this RCS is offered for the testing of existing drug products in conjunction with newly developed diagnostics, this RCS is, potentially, of particular importance in the context of personalized medicine. ${ }^{16}$

http://perma.cc/85QC-AHCP); FOOD \& DRUG ADMIN., Patent and Exclusivity Search Results from Query on Appl No 202570 Product 002 in the OB_Rx List, ORANGE BOOK, http://www.accessdata.fda.gov/scripts/cder/ob/docs/patexclnew.cfm?Appl_No=202570\&Pro duct_No=002\&tablel $=\mathrm{OB} \_R x$ (last visited Mar. 31, 2015) (archived at http://perma.cc/ZRF6-FR74); FOOD \& DRUG ADMIN., Patent and Exclusivity Search Results from Query on Appl No 202429 Product 001 in the OB_Rx List, ORANGE BoOK, $\mathrm{http} / /$ www.accessdata.fda.gov/scripts/cder/ob/docs/patexclnew.cfm?Appl_No=202429\&Pro duct_No $=001 \&$ table $1=O O_{2}$ Rx (last visited Mar. 31, 2015) (archived at http://perma.cc/5CVQ-LMLC); FOOD \& Drug Admin., Patent and Exclusivity Search Results from Query on Appl No 202806 Product 001 in the OB_Rx List, ORANGE BOOK, $\mathrm{http} / / / \mathrm{www}$. accessdata.fda.gov/scripts/cder/ob/docs/patexclnew.cfm?Appl_No=202806\&Pro duct_No $=001 \&$ table $=$ $=$ OB_Rx $\quad$ (last visited Mar. 31, 2015) (archived at http://perma.cc/6WZL-9AH8).

14 See Paving the Way, supra note 2, at 54.

15 See 21 U.S.C. $\S 355$ (c)(3)(E)(iii)-(iv) (2012). During that three-year period, the FDA is prevented from approving applications for generic versions of the drug product for that new medical use.

16 While the FDA's view is that "[i]deally, a therapeutic product and its corresponding [in vitro] companion diagnostic device should be developed contemporaneously," the FDA also "recognizes there may be cases when contemporaneous development may not be possible. An [in vitro] companion diagnostic device may be a novel [in vitro] device (i.e., a new test for a new analyte), a new version of an existing device developed by a different manufacturer, or an existing device that has already been approved or cleared for another purpose." In Vitro COMPANION DiAgNostics GuidanCE, supra note 7, at 7. 
A notable limitation on the availability of this RCS as a means of incentivizing such further testing of companion products is that this three-year RCS is, apparently, only available to the holder of the reference listed drug ("RLD"), who is also, typically, the beneficiary of a market exclusivity in the drug product itself. ${ }^{17}$ Thus, third parties who may be interested in further testing an already-approved drug product for a specific condition and/or in conjunction with a newly developed diagnostic cannot expect to benefit from this three-year RCS. This RCS is also unavailable for biological products, as BPCIA does not include an RCS for such additional clinical testing. ${ }^{18}$

Still, at least in some cases, RCSs of this type have been granted by the FDA to further the approval of certain drug products for the treatment of highly specific conditions "as detected by an FDA-approved test." 19 Hence, the threeyear market exclusivity under the Hatch-Waxman Act is, in fact, available for the development and testing of combination products consisting of diagnostic and therapeutic components. The FDA has also indicated that in other cases where, subsequently, a diagnostic is developed for use with a previously approved product, "it may be necessary to update the therapeutic product's labeling with appropriate test-related information if such information is essential for the safe and effective use of the product." 20 It is thus possible, at least hypothetically, that additional clinical testing by the RLD-holders leading to such labeling changes would trigger (or re-trigger) the onset of a three-year RCS under the Hatch-Waxman Act. ${ }^{21}$

It is quite possible that in some cases RLD-holders may be disincentivized to conduct such additional clinical trials that may result in the restriction of the potential user population of their drug products, even if such testing would make them eligible for the additional three-year RCS. In other cases, however,

17 See id. (specifying that the subsection applies to applications that contain "reports of new clinical investigations ... essential to the approval of the application and conducted or sponsored by the applicant [under subsection (b)]," (emphasis added) whereas the "applicant" under subsection (b) is the holder of the RLD application).

18 See 42 U.S.C $\$ 262(\mathrm{k})(7)(\mathrm{C})(2012)$.

19 See, e.g., FOOD \& Drug AdMIN., Patent and Exclusivity Search Results from Query on Appl No 202806 Product 001 in the OB_Rx List, ORANGE Book, http://www.accessdata.fda.gov/scripts/cder/ob/docs/patexclnew.cfm?Appl_No=202806\&Pro duct_No=001\&tablel=OB_Rx (last visited Mar. 31, 2015) (archived at http://perma.cc/6WZL-9AH8) (listing an additional three-year exclusivity for Tafinlar (Dabrafenib) as indicated for "Trametinib, in combination with Dabrafenib, for the treatment of patients with unresectable or metastatic Melanoma with BRAF V600E or V600K Mutations as detected by an FDA-approved test"); FOOD \& DRUG ADMIN., Exclusivity Codes (Definitions): Displaying Records 801 to 1000 of 1024, ORANGE BOOK, http:/www.accessdata.fda.gov/scripts/cder/ob/docs/excltermsall.cfm?firstRec=801 (last visited Mar. 31, 2015) (archived at http://perma.cc/3GRN-QMT4) (defining Exclusivity Code I - 678)

20 See PAVING THE WAY, supra note 2 , at 36.

21 The author is not aware of such cases as of the time of writing this Article. 
it is quite possible to envision how RLD-holders may benefit from conducting such additional clinical investigations of their existing pharmaceutical products in conjunction with in vitro diagnostic devices, which would make them eligible for the three-year RCS.22

The three-year RCS under the Hatch-Waxman Act has been criticized, however, as weak in light of the ease with which physicians prescribe FDA approved products "off label," including for indications that are absent from the labels of follow-on products (due to the existence of a patent or RCS covering that particular use). Yet, solutions to this problem have been offered and seem to be relatively easy to implement. ${ }^{23}$

\section{Pediatric Exclusivity Under the FDA Modernization Act of 1997 ("FDAMA") $)^{24}$}

Developers of original drug products may extend an existing RCS (under the Hatch-Waxman Act, BPCIA, or Orphan Drug Act) by "tacking on" 25 to these periods an additional term of six months of exclusivity for conducting clinical studies of the drug in pediatric populations. ${ }^{26}$ Importantly, like the three-year RCS discussed earlier, this exclusivity is only available to the holder of the reference listed drug $(R L D)$ and is not available for later applicants who may seek to receive an independent RCS on their follow-on product. While this RCS does not appear to incentivize the development of personalized treatments per se, it does promote further studies of existing drug products in pediatric populations, thereby making the tested product, potentially, more "individualized" or precise.

\section{A Six-Year Data Exclusivity in Class III Medical Devices ${ }^{27}$ Under the FDA}

22 This may occur, for example, where injuries resulting from the use of a specific drug (and subsequent tort liability) may be so frequent that "personalizing" the drug would make the drug product safer and, thus, more profitable for the RLD-holder. See, for example, the case of abacavir. PAVING THE WAY, supra note 2, at 39.

23 See Benjamin N. Roin, Solving the Problem of New Uses 36 (October 1, 2013) (unpublished manuscript), available http://papers.ssrn.com/sol3/papers.cfm?abstract_id=2337821 (archived at http://perma.cc/BG6Y-YGHS).

24 Food and Drug Modernization Act of 1997, Pub. L. No. 105-115, 111 Stat. 2296 (codified as amended in scattered sections of 21 U.S.C.).

25 See 21 U.S.C. $\S 355 \mathrm{a}(\mathrm{b})(1)$. The extension under FDAMA cannot stand alone when there is no prior exclusivity (RCS or patent) on which it may be "tacked."

26 See id. To clarify, the exclusivity applies to the product in general and not just to its use in a pediatric population; in fact, the exclusivity may apply even if the product is eventually not approved for use in the pediatric population.

27 Under the FDAMA, a Class III medical device is a device which (i) "cannot be classified as a class I" or "class II device because insufficient information exists to... provide reasonable assurance of its safety ... and (ii) ... is purported or represented to be for a use in supporting or sustaining human life or for a use which is of substantial 


\section{Modernization Act of 1997 (FDAMA) ${ }^{28}$}

Class III is the most heavily regulated tier of medical devices under FDA law, and devices classified as falling under this category require the approval by the FDA of a premarket application ("PMA"), which is subject to extensive data submission requirements. ${ }^{29}$ Once approved, Class III medical devices benefit from a period of six years of data exclusivity, during which the FDA may not use data submitted in connection with the PMA for the approval of follow-on versions of the approved device. ${ }^{30}$ It appears, however, that most diagnostics implicated in the area of personalized medicine are not classified by the FDA as Class III medical devices and, as such, are not the subject of the six-year data exclusivity under FDAMA. Notable examples of such devices are electroencephalographs ("EEG"), ${ }^{31}$ imaging devices, ${ }^{32}$ and certain genetic and gene-expression assays. ${ }^{33}$

Similarly, new and innovative uses of previously approved medical devices appear to be ineligible for any existing RCS. For example, a new technique for use of advanced imaging devices for the design and 3D printing of a personalized tracheal stint $^{34}$ does not appear to be subject to any RCS protection. ${ }^{35}$ It thus appears that most medical devices implicated in personalized medicine do not stand to benefit from existing RCSs either in the device itself or in new uses of previously approved devices in personalized medicine.

\section{ADDITIONAL WAYS OF USING RCSS TO INCENTIVIZE INNOVATION IN THE AREA OF PERSONALIZED MEDICINE}

The FDA has recently taken action to consolidate its regulation of

importance in preventing impairment of human health, or... presents a potential unreasonable risk of illness or injury." 21 U.S.C. $\$ 360 \mathrm{c}(\mathrm{a})(1)(\mathrm{C})$.

28 Food and Drug Modernization Act, 111 Stat. at 2296.

29 See 21 U.S.C. $\$ 360 \mathrm{e}(\mathrm{c})(1)$.

30 Food and Drug Modernization Act, $\S 216 ; 21$ U.S.C. $\S 360$ j(h)(4)(A).

3121 C.F.R. $\S 882.1400$ (2015) (electroencephalograph).

32 E.g., 21 C.F.R. $\S 892.1000$ (magnetic resonance diagnostic device); $\$ 892.1600$ (angiographic $\mathrm{x}$-ray system); $\S 892.1610$ (diagnostic $\mathrm{x}$-ray beam-limiting device); $\S$ 892.1630 (electrostatic $x$-ray imaging system); $\$ 892.1650$ (image-intensified fluoroscopic $\mathrm{x}$-ray system); $\S 892.1720$ (mobile $\mathrm{x}$-ray system); $\$ 892.1730$ (photofluorographic $\mathrm{x}$-ray system); $\S 892.1750$ (computed tomography $x$-ray system).

33 E.g., 21 C.F.R. $\S 864.7280$ (factor V Leiden DNA mutation detection systems); $\S$ 866.5900 (cystic fibrosis transmembrane conductance regulator (CFTR) gene mutation detection system); $\S 866.6040$ (gene expression profiling test system for breast cancer prognosis).

34 See Paving the WaY, supra note 2, at 9.

35 Notably, this may well comport with patent policy in the area of medical methods of treatment. See 35 U.S.C. $\S 287$ (c) (2012) (making remedies unavailable for patent infringement in the context of "medical activity"). 
diagnostics by, first, announcing a framework for regulatory oversight of laboratory-developed tests (LDTs, a.k.a. "home brews"), ${ }^{36}$ and, second, releasing final guidance on in vitro companion diagnostic devices. ${ }^{37}$ The increased regulatory burden that is likely to result from such newly established regulation might, arguably, dampen what the FDA describes as an "explosion" of products in the area of diagnostics in recent years. ${ }^{38}$ Instituting an additional RCS regime specifically for diagnostics may offset such an effect, but would require passing of new legislation. Notably, such legislation is already before Congress in the Modernizing Our Drug \& Diagnostics Evaluation and Regulatory Network Cures Act of 2013 ("MODDERN Cures Act of 2013"). ${ }^{39}$

36 Food \& Drug admin., Anticipated Detalls of the Draft Guidance for Industry, FoOd AND DRUg Administration STAFF, AND Clinical Laboratories: FRAMEWORK FOR REgUlatory OVERSIGHT OF LABORATORY DEVELOPED TESTS (LDTs):

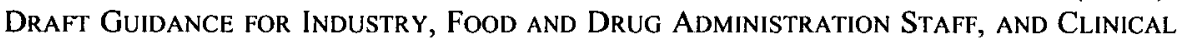
LABORATORIES

(2014), http:/www.fda.gov/downloads/MedicalDevices/ProductsandMedicalProcedures/InVitroDia gnostics/UCM407409.pdf (archived at http:/perma.cc/H88J-JXTS).

37 See In Vitro Companion Diagnostics Guidance, supra note 7.

38 PAVING THE WAY, supra note 2, at 23 ("Extraordinary advances across multiple scientific fields are leading to an explosion in diagnostic tests, but questions concerning appropriate evidentiary standards and regulatory oversight of these tests remain."); $i d$. at 30 ("[T] he sheer pace of the development of [in vitro diagnostics] over the past decade has been staggering. Volumes of information arising out of the human genome project combined with a dramatic decrease in costs of DNA sequencing, for example, are giving way to an explosion of publications linking particular genetic markers to diseases or conditions and a rapid application of this information in the development of new molecular diagnostic tests."). It is unclear, however, how these trends comport (if at all) with what appears to be a rather limited number of companion diagnostic devices approved by the FDA to date. See Food \& Drug AdMin., List of Cleared or Approved Companion DiAGNOSTIC DEVICES (IN VITRO AND IMAGING TOOLS), www.fda.gov/MedicalDevices/ProductsandMedicalProcedures/InVitroDiagnostics/ucm3014 31.htm (archived at http://perma.cc/JCX3-RD44) (listing only twenty diagnostic products approved by the FDA through January 2015). Notably, the number of companion diagnostic devices approved by the FDA remained almost the same at least since August 2013. See Alison M. Hill, Comment, Ambiguous Regulation and Questionable Patentability: A Toxic Future for In Vitro Companion Diagnostic Devices and Personalized Medicine?, 2013 WIS. L. REv. 1463, 1464-65 n.5, 1466 n.12 (2013) ("As of August 26, 2013, the FDA had approved only nineteen in vitro companion diagnostic devices."). But see FOOD \& DRUG ADMIN., Nucleic Acid Based Tests, http://www.fda.gov/MedicalDevices/ProductsandMedicalProcedures/InVitroDiagnostics/uc m330711.htm (archived at http://perma.cc/H5LM-263L) (listing another fifty-six human genetic test products approved by the FDA through January 27,2015 , not necessarily as companion diagnostics).

39 H.R. 3116, 113th Cong. $\$ 103$ (2013) (proposing an extension of the RCSs under the ODA, Hatch-Waxman Act, and BPCIA by 6-12 months for the development of diagnostics for use in conjunction with the therapeutic approved under these acts). 
Another option exists, however, that does not require the passage of new legislation, but only a change in FDA policy. The FDA could start requiring that prescribing information (a.k.a. labels) of pharmaceuticals having in vitro combination diagnostic devices mention specific devices approved by the FDA for use with such pharmaceuticals rather than the type of test, as the FDA currently requires. ${ }^{40}$ By doing so, the FDA would effectively "bind" such specific diagnostic device products to pharmaceutical products that are, potentially, covered by RCSs or whose indicated uses are covered by RCSs (in the case of drugs approved under the Hatch-Waxman Act and subject to the three-year RCS for additional clinical testing). This, of course, would not preclude some prescribers from prescribing any other comparable in vitro diagnostics for "off label" use in combination with such pharmaceuticals. Still it would effectively make the companion diagnostic mentioned by name in the prescribing information the default diagnostic for use in conjunction with the prescribed pharmaceutical unless a prescriber explicitly prescribes a different diagnostic product. While the economic value of such a benefit would greatly depend on the circumstances of the specific diagnostics' market prescribed in conjunction with a given product, it would presumably be higher than zero (which is what it is now) and, potentially, significant. This, in turn, may create added incentives to develop and be the first to have approved in vitro diagnostic products for use in conjunction with specific pharmaceutical products.

Importantly, however, it appears that the FDA does not believe that this course of action is desirable, as it explicitly requires that "[t]he therapeutic product labeling should specify use of an FDA approved or cleared [in vitro] companion diagnostic device, rather than a particular manufacturer's [in vitro] companion diagnostic device." 41 The reasoning provided for this policy by the FDA is that "[t]his will facilitate the development and use of more than one approved or cleared [in vitro] companion diagnostic device of the type described in the labeling for the therapeutic product."42 It appears that the FDA is well aware of the possibility of requiring the use of a specific in vitro companion diagnostic in a therapeutic's label as a means of providing competitive benefits in the diagnostic product, but does not believe that such benefits are necessary for incentivizing further development of in vitro companion diagnostics.

The FDA's position begs the question whether and to what extent is there a need for additional incentives for innovation in the area of diagnostics, given what the FDA brands as the explosion in data and products in this area over the

40 See 21 C.F.R. $\$ 201.57(\mathrm{c})(6)(\mathrm{iii})$ (2015); In Vitro Companion Diagnostics GUIDANCE, supra note 7, at 11 ("If a diagnostic test is essential for monitoring either therapeutic or toxic effects, the type of test must be identified under Warnings and Precautions."').

41 In Vitro COMPANION Diagnostics Guidance, supra note 7, at 11.

42 Id. 
last decade. ${ }^{43}$ It appears that at least some do not share the FDA's optimism regarding the sufficiency of current incentives for innovation in the area of diagnostics. ${ }^{44}$

To mitigate possible risks of over-protection of personalized medicine technology, it is also advisable to provide newly approved diagnostic products with data exclusivity rather than market exclusivity. The advantage of data exclusivity is that it works its effect by conferring a competitive advantage on its beneficiary only if and when the data protected under the exclusivity is actually valuable. In other words, where the independent development of a similar dataset for a competing product would not be prohibitively expensive given the realities of the market in the diagnostic, the data exclusivity in the original product will not deter potential competitors seeking to have their own competing diagnostic product approved by the FDA.

Another option is to adopt an RCS regime in medical diagnostics similar to the one established under the Federal Insecticide, Fungicide, and Rodenticide Act (FIFRA). ${ }^{45}$ Under the FIFRA RCS regime, the developer of a new product benefits from a ten-year data exclusivity period, which is then followed by another period of five years during which the data is available to third parties, but "only if the [third party] applicant [for the follow-on product] has made an offer to compensate the original data submitter." 46

\section{CONCLUSION}

While existing RCS regimes cover some personalized medicine technologies, there seems to be very little protection afforded under these regimes to diagnostic technologies. Additional RCS protection for diagnostics may be provided via legislation such as the MODDERN Cures Act. Alternatively-and more feasibly - the FDA may provide further incentives for the development of diagnostics by requiring the mentioning of specific diagnostic products in labels of therapeutics with which such diagnostics are combined. Regardless, unless and until it is clear that the area of diagnostics suffers from a lack of sufficient incentives for innovation, it is preferable that any new competitive benefit proffered to diagnostic products would not consist of market exclusivity.

43 See H.R. $3116 \S 103$.

44 See Editorial, Myriad Diagnostic Concerns, 31 Nature BIOTECH. 571 (2013) (arguing that the combination of the Myriad and Prometheus decisions, the FDA's anticipated increased oversight of laboratory tests and diagnostics, and concerns regarding reimbursement by insurance companies are "the death knell for diagnostic innovation," as evidenced by decreased private investment in the diagnostics sector).

45 Federal Insecticide, Fungicide, and Rodenticide Act (FIFRA), ch. 125, 61 Stat. 163 (1947) (codified at 7 U.S.C. $\S \S 136-136 y(2012)$ ).

467 U.S.C. $\$ 136 \mathrm{a}(\mathrm{c})(1)($ F)(iii) (2012). For further discussion of the FIFRA RCS regime, see Heled, supra note 3, Part II.A. 